\title{
Toric Intraocular Lens Results Considering Posterior Corneal Astigmatism with Online Calculators: Phacoemulsification vs. Femtosecond
}

\author{
Joaquín Fernández ${ }^{1}$, Manuel Rodríguez-Vallejo ${ }^{1, *} \mathbb{C}$, Noemí Burguera ${ }^{1}$, Patrizia Salvestrini ${ }^{1}$ \\ and Nuria Garzón ${ }^{2}$ (D) \\ 1 Department of Ophthalmology (Qvision), VITHAS Hospital, 04120 Almería, Spain; \\ joaquinfernandezoft@qvision.es (J.F.); noemiburgueraid@qvision.es (N.B.); patrisalvestrini@gmail.com (P.S.) \\ 2 Optometry and Vision Department, Faculty of Optics and Optometry, \\ Complutense University of Madrid (Garzón), 28037 Madrid, Spain; nugarzon@opt.ucm.es \\ * Correspondence: manuelrodriguezid@qvision.es
}

check for

updates

Citation: Fernández, J.;

Rodríguez-Vallejo, M.; Burguera, N.;

Salvestrini, P.; Garzón, N. Toric

Intraocular Lens Results Considering

Posterior Corneal Astigmatism

with Online Calculators:

Phacoemulsification vs. Femtosecond.

Optics 2021, 2, 184-192. https://

doi.org/10.3390/opt2030017

Academic Editor: Feruz Ganikhanov

Received: 19 July 2021

Accepted: 1 September 2021

Published: 3 September 2021

Publisher's Note: MDPI stays neutral with regard to jurisdictional claims in published maps and institutional affiliations.

\begin{abstract}
To evaluate the prediction error (PE) obtained in Phacoemulsification (Phaco) or Femtosecond (Femto) surgeries without considering posterior corneal astigmatism correction (non-PCA) versus the correction based on Abulafia-Koch + Medicontur (AK) and Barrett calculators in toric intraocular lens (IOL) power calculation. 58 right eyes were retrospectively retrieved from our database. Two groups formed by 28 and 30 eyes depending on the surgery type, Phaco or Femto respectively, were defined. Astigmatism PE were evaluated considering the approach used for calculation of the implanted IOL power (AK) versus the estimation of PEs in non-PCA and Barrett formula. A doubly-multivariate analysis was conducted to assess the differences between-surgery types, within-methods of calculation, and interaction. Mean centroid PE was significantly different between non-PCA, AK and Barrett approaches $(p<0.0005)$, and neither differences $(p<0.239)$ nor interaction $(p=0.672)$ between Phaco or Femto were found. Post-hoc univariate analysis showed a higher PE for the x-component of the non-PCA method versus AK $(0.15 \mathrm{D}, p<0.0005)$ and non-PCA versus Barrett $(0.18 \mathrm{D}, p<0.0005)$, though no differences were found between $\mathrm{AK}$ and Barrett $(0.03 \mathrm{D}$, $p=0.93$ ). Against-the-rule under-correction and with-the-rule overcorrection were found in both arms when PCA was not considered. Both calculators provide comparable clinical results.
\end{abstract}

Keywords: toric intraocular lens; prediction error; posterior corneal astigmatism; femtosecond; phacoemulsification

\section{Introduction}

Although traditionally only anterior corneal astigmatism has been considered to calculate the intraocular lens (IOL) power, posterior corneal surface also contributes to total corneal astigmatism. Koch et al. reported that ignoring posterior corneal astigmatism (PCA) may yield an incorrect estimation of total corneal astigmatism [1]. Although the refractive power of the posterior surface is much smaller than the anterior surface due to the small difference in refractive index between the cornea and the aqueous humor, an overcorrection in with-the-rule (WTR) and an under-correction with against-the-rule (ATR) anterior corneal astigmatism could be expected if the PCA is not considered in the calculation [1].

There are different methods to assess total corneal astigmatism in order to calculate the IOL power. Some authors estimate PCA on the basis of anterior corneal astigmatism [1-4], others measure the posterior astigmatism with tomography [5] or estimate total corneal astigmatism based on the anterior-to-posterior corneal cylinder power ratio [6]. The Abulafia-Koch (AK) regression formula for IOL power calculates the estimated total corneal astigmatism using standard keratometry $(\mathrm{K})$ measurements [4]. This formula adjusts standard $\mathrm{K}$ measurements to the estimated net corneal power, thereby 
requiring independent calculation of IOL spherical power though facilitating the formula's use with any toric IOL calculator. The Barrett toric calculator (available at http:/ / www.ascrs.org/barrett-toric-calculator (accessed on 1 December 2020)) uses the Universal II formula [7] to calculate an effective lens position, which is also influenced by the spherical equivalent and cylindrical toric IOL power. This online calculator predicts PCA using an algorithm or allows for entering the measured PCA as well.

The main aim of this study was to evaluate the clinical results obtained without considering PCA correction (non-PCA) versus the correction based on AK + Medicontur and Barrett calculators. Both methods estimate PCA mathematically based on anterior surface measurements only. A secondary aim was to evaluate whether prediction error (PE) differed between Phacoemulsification (Phaco) and Femtosecond Laser Cataract Surgery (Femto).

\section{Materials and Methods}

\subsection{Subjects and Procedures}

This study was approved by the Ethics Committee of Research, Almería Center, Torrecárdenas Hospital Complex, and conducted in adherence with the tenets of the Declaration of Helsinki. The data of 58 right eyes of patients, ranging from 51 to 88 years old, previously operated on cataracts with the implantation of a monofocal toric IOL at Qvision (Department of Ophthamology, Hospital Vithas Virgen del Mar, Almería) were reviewed. Inclusion criteria were eyes with anterior preoperative corneal astigmatism $\geq 0.9 \mathrm{D}$ measured using IOL Master 500 (Carl Zeiss Meditec AG, Jena, Germany) for which the implantation of a toric IOL is recommended [8]. Eyes with postoperative corrected distance visual acuity (CDVA) $>0.3 \log M A R$ were excluded from the analysis according to standard recommendations [9]. Other exclusion criteria were irregular astigmatism, acute or chronic disease or illness that would increase risk or confound study results, history of ocular trauma or prior ocular surgery including refractive procedures, capsule or zonular abnormalities that may affect postoperative centration or tilt of the IOL, pupil abnormalities and AMD suspicious eyes. Subjective refraction was obtained at 1-month follow-up by two experienced optometrists trained to follow the same procedure of refraction measured at $4 \mathrm{~m}$ and adjusted to infinity by means of adding $-0.25 \mathrm{D}$ to the refraction according to international standard recommendations [10]. Visual acuities were also measured with an ETDRS chart before and after refraction procedure without and with best correction, respectively [9].

\subsection{Surgery and Intraocular Lens}

All eyes were operated by the same surgeon (JF) through temporal corneal clear incisions conducted manually ( $2.2 \mathrm{~mm}$ length) prior to Phaco surgery or conducted by laser (2.5 mm length) prior to Femto (Victus; Technolas Perfect Vision GmbH, Munich, Germany), according to the current clinical practice and patient's decision. The same monofocal toric intraocular lens Bi-Flex T 677TA (Medicontur Medical Engineering Ltd. Inc., Zsámbék, Hungary) was implanted in all eyes. Toric IOLs were intraoperative aligned with the help of ink marks performed with pendulum (J2281, e. Janach srl, Italy) at the surgery room with the patient in an upright position to prevent cyclotorsion in the supine position. Next, with the patient lying down, marks were made at the implanting IOL position using a Mendez ring (J2295.5, e. Janach srl, Italy).

The implanted cylindrical power was calculated using the Medicontur IOL Optimizer calculator (https: / / toriccalculator.net/ (accessed on 1 December 2020)) entering the anterior corneal keratometry data measured with the IOL Master 500 and applying the AK correction [4]. Surgeon's mean corneal surgically induced astigmatism was not considered in the calculation of the implanted IOL power which was calculated considering the PCA estimated with AK. The predicted residual astigmatism was obtained for the three methods (non-PCA, AK and Barrett correction) considering the implanted IOL power. To compare the results with the Barrett Toric Calculator (https: / / ascrs.org/tools/barrett-toric-calculator (accessed on 1 December 2020)), we also registered the predicted astigmatism for the implanted IOL cylindrical power. 


\subsection{Statistical Analysis}

Only right eyes were included in the analysis [11]. The study endpoint was the PE calculated as the vector difference between the actual and the predicted postoperative refractive astigmatism at the corneal plane $[12,13]$ for the three methods considered as repeated measurements in the same subjects (within-subjects effect). The surgery type, either Phaco or Femto, was considered as the independent variable (between-subjects effect). A doubly multivariate analysis was conducted due to the characteristics of the study design: two dependent variables ( $X$ and $Y$ orthogonal components of astigmatism in a double angle plot) repeated three times (non-PCA, AK and Barrett) in two independent groups (Femto and Phaco) [14]. A post-hoc univariant analysis with Bonferroni correction was applied for detecting the differences between prediction errors for each astigmatism component among the three methods of calculation. All figures and vector analysis calculations were conducted with the Refractive Analysis Toolbox (v1.0.4) for Matlab (R2019; MathWorks, Natick, MA, USA) [15]. Data analysis was carried out using the IBM SPSS for windows statistical software (version 24.0; SPSS, Inc., Chicago, IL, USA).

\section{Results}

29 men and 29 women were included in the analysis, 28 eyes operated on with Phaco and 30 with Femto. Table 1 shows the demographic characteristics of the sample with older subjects in the Phaco group $(p=0.004)$.

Table 1. Descriptive analysis for demographic variables.

\begin{tabular}{cccc}
\hline Variable & $\begin{array}{c}\text { Phaco } \\
\text { Mean } \pm \text { SD; Median (IQR) }\end{array}$ & $\begin{array}{c}\text { Femto } \\
\text { Mean } \pm \text { SD; Median (IQR) }\end{array}$ & Statistic; $\boldsymbol{p}$-Value \\
\hline N (WTR, Oblique, ATR) & $28(8,3,17)$ & $30(12,8,10)$ & $\chi^{2}=4.82 ; 0.1$ \\
Age & $73.93 \pm 10.43 ; 75(12)$ & $67.43 \pm 8.36 ; 69(13.75)$ & $\mathrm{z}=605 ; 0.004 *$ \\
Anterior Corneal Preoperative & $1.89 \pm 0.70 ; 1.70(0.74)$ & $1.76 \pm 0.63 ; 1.57(0.63)$ & $\mathrm{Z}=490 ; 0.276$ \\
Astigmatism (D) & $24.06 \pm 1.58 ; 23.87(1.08)$ & $24.25 \pm 1.85 ; 23.81(2.32)$ & $\mathrm{z}=416 ; 0.85$ \\
Axial length (mm) & $3.09 \pm 0.34 ; 3.08(0.50)$ & $3.07 \pm 0.45 ; 3.02(0.63)$ & $\mathrm{t}=-0.245 ; 0.808$ \\
Anterior chamber depth (mm) & $0.12 \pm 0.1 ; 0.1(0.2)$ & $0.13 \pm 0.15 ; 0.1(0.22)$ & $\mathrm{Z}=540 ; 0.057$ \\
Postoperative CDVA & $0.21 \pm 0.15 ; 0.2(0.2)$ & $17.58 \pm 5.56 ; 19.5(6.63)$ & $\mathrm{z}=608 ; 0.002 *$ \\
Postoperative UDVA & $19.20 \pm 3.72 ; 20(4)$ & $2 \pm 0.84 ; 2.25(0.88)$ & $\mathrm{z}=476 ; 0.383$ \\
Intraocular lens power for & Sphere (D) & $2.42 \pm 1.09 ; 2.25(1.50)$ & $\mathrm{Z}=513 ; 0.136$ \\
Intraocular lens power for & &
\end{tabular}

WTR: with-the-rule; ATR: against-the-rule; N: Number of eyes; SD: Standard deviation; IQR: Inter-quartile range; $\chi^{2}$ : chi-square; t: student $t$-test for independent samples; $\mathrm{z}$ : Mann-Whitney test; * $p<0.05$.

PE for the Phaco group in Non-PCA, AK and Barret are shown in Figure 1B-D, respectively. On the other hand, Figure $1 \mathrm{~F}-\mathrm{H}$ show the respective results for the Femto group. Under-correction of the ATR was found in the Phaco group for the non-PCA correction $(0.14 \pm 0.62) 174^{\circ}$, even though the $95 \%$ CI for the centroid contained the zero value (center of coordinates) (Figure 1B), whereas the Femto group resulted in an overcorrection of the preoperative WTR astigmatism $(0.22 \pm 0.46) 9^{\circ}$ (Figure $\left.1 \mathrm{~F}\right)$ with the $95 \% \mathrm{CI}$ for the centroid not containing the zero value. The under-correction of ATR and overcorrection of WTR from both groups decreased in both cases, after AK correction (Figure 1C for Phaco and Figure 1G for Femto) and Barret correction (Figure 1D for Phaco and Figure $1 \mathrm{H}$ for Femto).

Figure 1A,E show the double angle plot for the preoperative astigmatism in the Phaco and Femto groups, respectively. Mean centroid was located at the ATR side for Phaco $(0.66 \pm 1.94 \mathrm{D}) @ 8^{\circ}$ and in the WTR side for Femto $(0.32 \pm 1.88 \mathrm{D}) @ 103^{\circ}$ even though no significant differences in proportions were found (Table 1 ). 


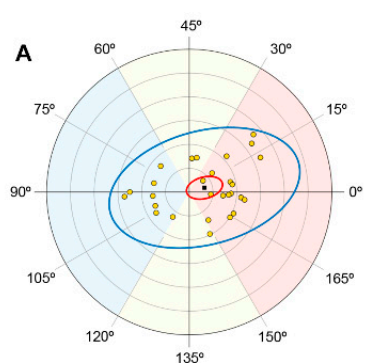

- Centroid: $0.66 @ 8^{\circ}+/-1.94$ D; N = 28

O $95 \%$ confidience ellipse of the centroif
$0.95 \%$ confidence ellipse of the datased

Each ring $=1.00 \mathrm{D}$

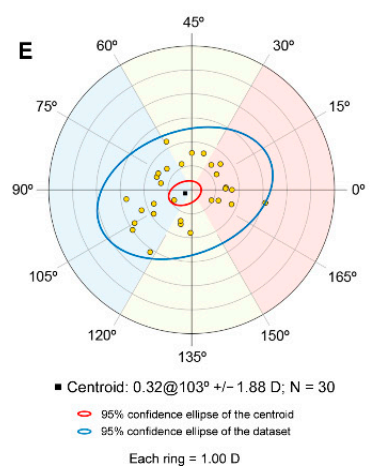

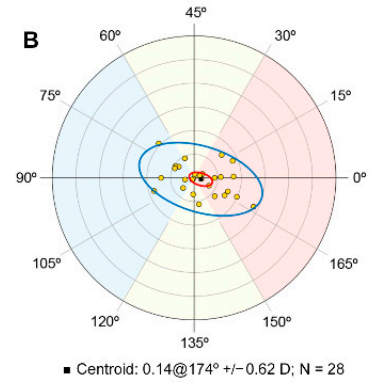

- Centroid: $0.14 @ 174^{\circ}+1-0.62 \mathrm{D} ; \mathrm{N}=$

O $95 \%$ confidence ellipse of the centroid
O $95 \%$ confidence ellipse of the dataset

Each ring $=0.50 \mathrm{D}$

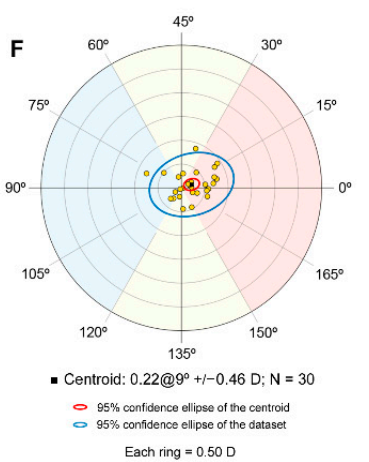

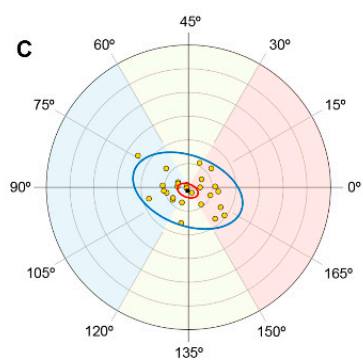

- Centroid: $0.07 @ 127^{\circ}+/-0.58 \mathrm{D} ; \mathrm{N}=28$ $-95 \%$ confidence ellipse of the centrolid
O $95 \%$ confidence ellipse of the datast Each ring $=0.50 \mathrm{D}$

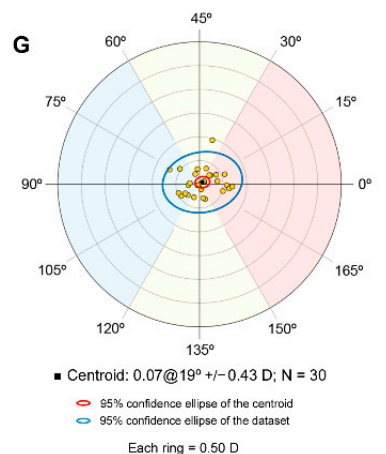

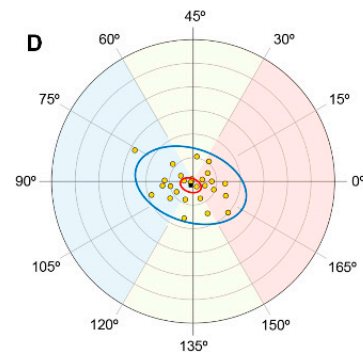

- Centroid: $0.10 @ 118^{\circ}+1-0.59 \mathrm{D} ; \mathrm{N}=28$ O $95 \%$ confidence ellipse of the centroid Each ring $=0.50 \mathrm{D}$

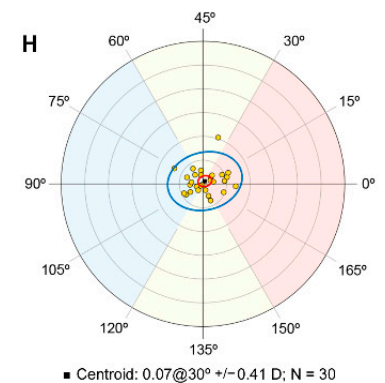
- $95 \%$ confidence ellipse of the centroid

Each ring $=0.50 \mathrm{D}$

Figure 1. Preoperative anterior corneal astigmatism in the Phaco group (A) and prediction errors without considering posterior corneal astigmatism (B), estimation with Abulafia-Koch formula (C) and Barrett formula (D). Preoperative anterior corneal astigmatism in the Femto group (E) and prediction errors without considering posterior corneal astigmatism (F), estimation with Abulafia-Koch formula $(\mathbf{G})$ and Barrett formula $(\mathbf{H})$.

The differences between Femto and Phaco groups on the combined dependent variables were not statistically significant, $F(2,55)=1.469, p<0.239$; Wilks' $\Lambda=0.949$; partial $\eta^{2}=0.051$. However, significant differences were found between the combined dependent variables and the three calculation methods $\mathrm{F}(4,53)=7.921, p<0.0005$; Wilks' $\Lambda=0.626$; partial $\eta^{2}=0.374$. No interaction was found between the surgery type and the three calculation methods F $(4,53)=0.589, p=0.672$; Wilks' $\Lambda=0.957$; partial $\eta^{2}=0.043$. The post-hoc univariate analysis showed that differences were for the $X$ component between the non-PCA and both methods, AK and Barrett, although no significant differences found were between AK and Barrett calculators (Table 2).

Table 2. Pairwise comparisons with Bonferroni correction.

\begin{tabular}{ccc}
\hline Preoperative Type & Mean Difference $\mathbf{9 7 . 5 \%}$ CI) & $p$-Value \\
\hline X (D) & $0.15(0.08$ to 0.23$)$ & $<0.0005$ \\
Non-PCA-AK & $0.18(0.08$ to 0.29$)$ & $<0.0005$ \\
Non-PCA-Barret & $0.03(-0.05$ to 0.10$)$ & 0.925 \\
AK-Barrett & & \\
Y (D) & $0.04(-0.02$ to 0.09$)$ & 0.18 \\
Non-PCA-AK & $0.03(-0.02$ to 0.09$)$ & 0.32 \\
Non-PCA-Barret & $-0.002(-0.03$ to 0.03$)$ & 1.0 \\
AK-Barrett &
\end{tabular}

Figure 2 shows the descriptive statistics for the cumulative astigmatism prediction error for the Phaco $(\mathrm{A}, \mathrm{B}, \mathrm{C})$ and the Femto $(\mathrm{D}, \mathrm{E}, \mathrm{F})$ groups in paired comparison between calculation methods. Higher percentage of eyes in lower prediction error levels were obtained for both surgery types in the AK and Barrett PCA correction versus the non- 
PCA correction, although these were more remarkable in the Femto group and Barrett correction (Figure 2F).
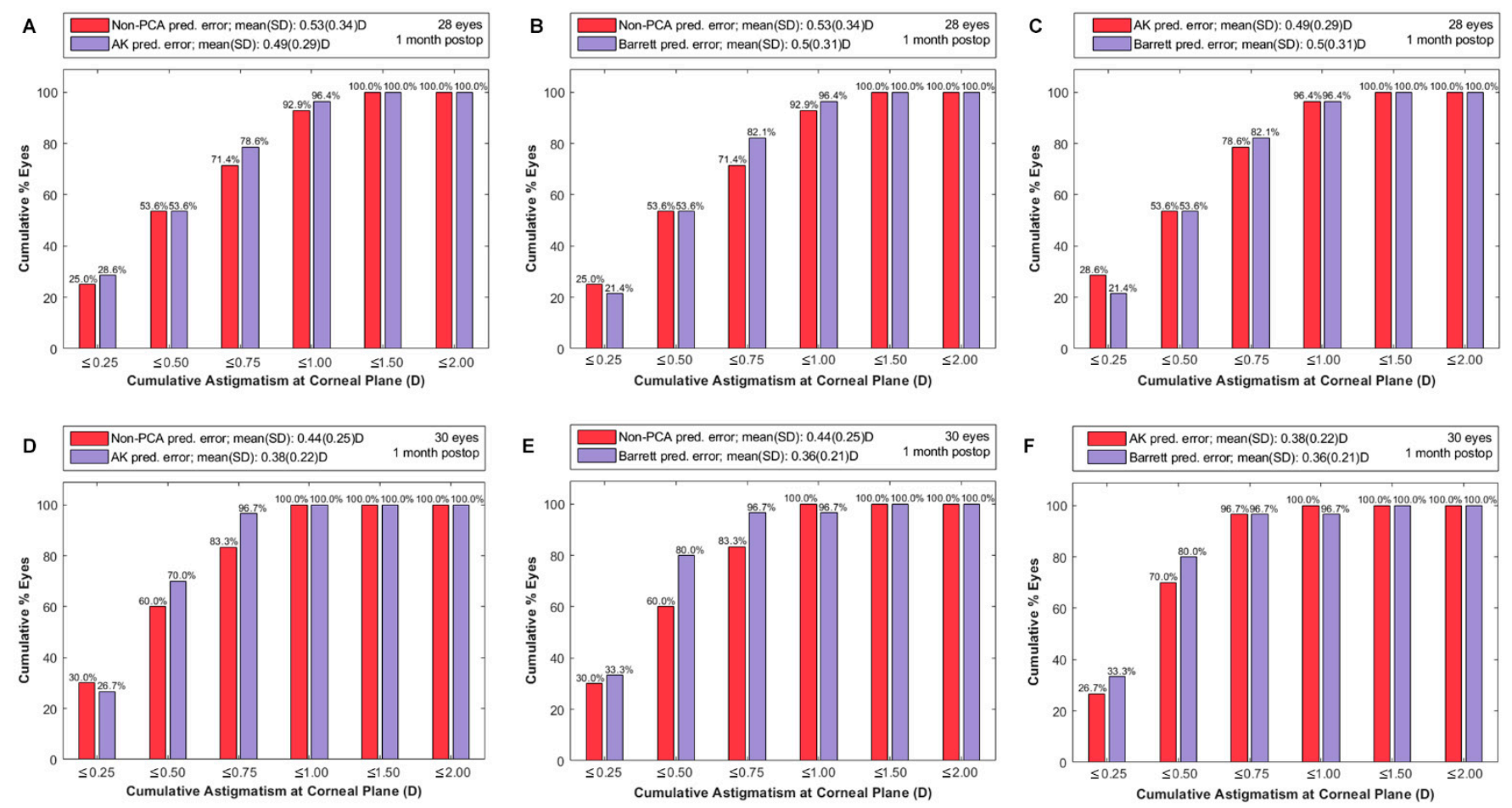

Figure 2. Cumulated percentage of eyes below or equal to a particular value for the astigmatism prediction error in the Phaco group without considering posterior corneal astigmatism [non-PCA] versus Abulafia-Koch [AK] estimation (A), non-PCA versus Barrett estimation (B) and AK versus Barrett (C). Same calculations for the Femto group in non-PCA vs. AK (D), non-PCA vs. Barrett (E) and AK vs. Barrett (F).

\section{Discussion}

Residual postoperative astigmatism is an important cause for not achieving emmetropia after cataract surgery. Patients increasingly demand satisfactory postoperative visual function, to the maximum of their potential, after cataract extraction. Astigmatism correction results in significantly improved visual acuity at all contrast levels at both distance and near [16] and enhances visual outcomes and patients' satisfaction after cataract surgery. About $30 \%$ of cataract patients exhibit higher than $0.75 \mathrm{D}$ of corneal astigmatism that would require correction to attain maximum uncorrected visual outcomes [17,18]. Lately, several new algorithms have been developed that incorporate the effect of PCA in toric IOL power determination, reporting the benefits of incorporating the contribution of the posterior corneal surface in the postoperative outcomes after monofocal and toric IOL implantation [4,19-22]. In this study, we evaluated the accuracy of two calculators, Medicontur and Barrett calculators, to reduce the astigmatism PE considering the formulas included for PCA correction, AK and Barrett, respectively.

Abulafia et al. [4] already compared the calculations obtained with AK and Barrett formula, as we have evaluated with the Medicontur calculator, but with the Alcon and Holladay toric calculators. In agreement with our study, their results were more accurate with AK and Barrett, and both formulae yielded similar results in PE through the estimation of PCA using anterior cornea-based K measurements. The mean centroid in PE with the Barrett toric calculator $(0.05 \mathrm{D})$ was not significantly different when the AK formula was applied with the Alcon $(0.05 \mathrm{D})$ and Holladay $(0.04 \mathrm{D})$ toric calculators. In agreement with Abulafia et al. [4], Ferreira et al. [21] also reported similar results, with no significant differences, for the centroid PE between Holladay calculator and the AK formula to the Barrett calculator. Nanavaty et al. [23] also reported better results with the estimation 
of PCA with the Rayner calculator, similar to the Barrett estimation, and Yeu et al. [24] confirmed the results previously obtained by Abulafia et al. [4] for the Alcon calculator.

Unlike Abulafia et al. [4] and Ferreira et al. [21] who used the postoperative corneal power and considered the IOL power change due to postoperative rotations, our study followed a different approach. The approach followed by these authors lead to identify that the PE was due to the postoperative PCA avoiding corneal SIA and IOL rotation noise, whereas we used the total SIA as the difference between the postoperative refractive astigmatism and the preoperative corneal power [25]. Total SIA allows to evaluate the accuracy of the calculation method, but it has the disadvantage of not allowing to identify possible sources that can lead to an accuracy error or to the success. Despite following different approaches, our conclusions agree with the previous authors for another calculator not previously reported in the literature, the Medicontur calculator, which in combination with the AK formula leads to similar results than the Barrett Toric calculator in the estimation of PCA, according to our findings.

Our study also observed that formulas for PCA estimation improved the accuracy for either Phaco or Femto. According to a previous study, [26] Manual and Femto temporal corneal incisions resulted in a corneal SIA of 0.14 D@65 $5^{\circ}$ and $0.24 \mathrm{D} @ 92^{\circ}(p>0.05)$, respectively, with a higher bias in the manual incisions. These corneal SIA results were derived from anterior corneal measurements and there are no clinical studies evaluating the impact of considering the corneal SIA in PE derived from anterior corneal measurements in combination with algorithms for PCA since previous studies avoided corneal SIA noise, including just postoperative corneal measurements [4,21]. Only Cánovas et al. [3] compared their own model of PCA estimation in two scenarios, combination of estimated corneal SIA + preoperative corneal power versus postoperative corneal power, obtaining better results in the postoperative corneal power than the combination of preoperative + estimated SIA, both without considering PCA, whereas considering PCA in both approaches resulted in similar results. Nevertheless, Cánovas et al. [3] did not evaluate results with preoperative corneal power and did not consider the estimated SIA, as this parameter was provided by the surgeons based on their experience but not directly measured in the study. In our study, considering the magnitude of the low non-significant prediction errors in Phaco (0.07@127 $)$ and Femto (0.07@19 $)$ after the application of the AK formula with vector addition to the previously reported anterior corneal SIA of $0.14 \mathrm{D} @ 65^{\circ}$ and $0.24 \mathrm{D} @ 92^{\circ}$, respectively, it would have resulted in an increase of the PE to $0.11 @ 80^{\circ}$ and $0.19 @ 86^{\circ}$, respectively. The combination of SIA derived from total cornea and these algorithms should be also evaluated in future studies because latest research suggests that corneal SIA differs between the derived from anterior cornea and total cornea [27,28]. Kohnen et al. [29] reported differences in the percentage of eyes with anterior corneal SIA $<0.25 \mathrm{D}$ in WTR and ATR cases but these differences were completely reduced when total cornea was considered suggesting that these incisions can be considered as neutral due to the minimal induced astigmatism. In our opinion, some caution should be borne in mind by surgeons using estimated anterior corneal SIA and PCA algorithms until future studies provide evidence if the combination improves or aggravates the results.

When Ferreira [21] compared AK and Barrett toric calculator, both calculators resulted in ATR prediction errors. In our study, when the estimation of PCA was no considered in the calculations, the ATR prediction error was obtained with both techniques. Kern et al. [30] also evaluated two methods, one of them using only corneal front keratometric values and the use of estimated PCA with Barrett calculator. He found that the use of only anterior astigmatism may lead to postoperative under-correction of astigmatism as we have found in our study, under correction of ATR (Phaco) and overcorrection of WTR (Femto) for the non-PCA calculations. These results can be explained based on the expected overcorrection in WTR astigmatism and undercorrection in ATR astigmatism, as it is often described in the literature [31,32].

Abulafia et al. [4] found a higher proportion of eyes within $\pm 0.50 \mathrm{D}$ of the predicted residual astigmatism when formulae that estimate the power of the PCA-based on anterior 
surface measurements were used (range from $76.9 \%$ to $79.5 \%$,) compared to not considering PCA $(30.8 \%)$. Cánovas et al. [3] showed a $45 \%$ of patients within $\pm 0.50 \mathrm{D}$ with non PCA, and $57 \%$ when PCA was considered. Kane et al. [33] reported percentages of $53.7 \%$ and $53.8 \%$ for Barret and AK, respectively. In our study, identical results were obtained for the Phaco group with the non-PCA, AK and Barrett calculations ( $53.6 \%$ patients within $\pm 0.50 \mathrm{D})$ but significant different results for the Femto group when the three methods were compared ( $60 \%$ patients within $\pm 0.50 \mathrm{D}, 70 \%$ and $80 \%$ for Non-PCA, AK and Barrett respectively).

We consider that it is important to highlight that although non-significant mean differences were obtained in our study between Phaco and Femto groups, standard deviation was higher in the Phaco group as it can be seen in the double angle plots resulting in a higher percentage of eyes achieving higher accuracy levels for the Femto group. However, due to the retrospective characteristics of the study and the older age of the Phaco group, no conclusion may be withdrawn as the observed differences might be attributed to surgery type or to the patients' age, as age acts as a confounding factor. Furthermore, posthoc statistical power was calculated (G-Power 3.1.9.2, https:/ / www.psychologie.hhu.de/ (accessed on 1 December 2020)) for $n=58$ and a Type I error of $\alpha=0.05$ obtaining $1-\beta=0.6$ for a partial $\eta^{2}$ of 0.076 in between factors (Phaco/Femto) comparison obtained in the study. On the other hand, power was 1.0 for within methods of calculation (Non-PCA, AK and Barrett) and a partial $\eta^{2}$ of 0.375 . This means that even though sample size was enough for within calculation methods, a Type II error might be happened for the small effect size obtained between factors (Phaco/Femto). Some theoretical explanations might be attributed to both hypotheses. Firstly, there is a linear relationship between the difference of total and keratometric astigmatism that might lead to a poorer performance of the correction by the regression algorithms in older subjects [34]. However, differences might be also explained due to surgeon corneal SIA or rotational stability of the IOL, as corneal incisions and capsulotomy also differed between groups [26]. Future studies not based in total SIA and with a more uniform age gap between groups are required to evaluate whether femtosecond laser cataract surgery might result in a higher accuracy.

\section{Conclusions}

Based on our results and in agreement with previous authors, the importance of PCA in predicting postoperative refraction after toric lens implantation is clear. Despite the percentage of eyes achieving a higher accuracy was slightly better with Barrett than AK, the lack of significant mean differences in the pairwise comparison shows that this slightly high percentage might be attributed to chance. In any case, with both methods, the results were better that the ones obtained when posterior astigmatism was not considered. On the other hand, despite of the clear limitations of the study to obtain conclusions about accuracy of Phaco or Femto, the differences between non-PCA, AK and Barrett corrections were uniform for both procedures, as no interaction was observed between the calculation and surgery types by the doubly multivariate profile analysis. This means, that either in Phaco or Femto procedures, using any of both regression algorithms will improve the results in comparison to not calculating PCA. Finally, future studies should investigate the results in the combination of anterior or posterior corneal derived SIA with these algorithms to estimate PCA.

Author Contributions: Conceptualization, J.F., M.R.-V. and N.G.; methodology, J.F., M.R.-V., P.S. and N.B.; software, M.R.-V.; formal analysis, J.F., M.R.-V. and N.G.; resources, J.F.; data curation, M.R.-V., P.S. and N.B.; writing—original draft preparation, J.F., M.R.-V. and N.G.; writing—review and editing, P.S. and N.B.; supervision, J.F.; project administration, J.F.; funding acquisition, J.F. All authors have read and agreed to the published version of the manuscript.

Funding: This research received no external funding.

Institutional Review Board Statement: The study was conducted according to the guidelines of the Declaration of Helsinki, and approved by the Ethics Committee of Research, Almería Center, Torrecardenas Hospital Complex (protocol code QV-20-04, approved date 28 October 2020). 
Informed Consent Statement: Informed consent was not required for this study design.

Acknowledgments: Not applicable.

Conflicts of Interest: Fernández is consultant from Medicontur. No other author has a financial or proprietary interest in any material or method mentioned.

\section{References}

1. Koch, D.D.; Ali, S.F.; Weikert, M.P. Contribution of posterior corneal astigmatism to total corneal astigmatism. J. Cataract Refract. Surg. 2012, 38, 2080-2087. [CrossRef]

2. Yoon, C.H.; Kim, M.K. Improving the toric intraocular lens calculation by considering posterior corneal astigmatism and surgically-induced corneal astigmatism. Korean J. Ophthalmol. 2018, 32, 265-272. [CrossRef]

3. Canovas, C.; Alarcon, A.; Rosén, R.; Kasthurirangan, S.; Ma, J.J.K.; Koch, D.D.; Piers, P. New algorithm for toric intraocular lens power calculation considering the posterior corneal astigmatism. J. Cataract Refract. Surg. 2018, 44, 168-174. [CrossRef]

4. Abulafia, A.; Koch, D.D.; Wang, L.; Hill, W.E.; Assia, E.I.; Franchina, M.; Barrett, G.D. New regression formula for toric intraocular lens calculations. J. Cataract Refract. Surg. 2016, 42, 663-671. [CrossRef] [PubMed]

5. Reitblat, O.; Levy, A.; Kleinmann, G.; Abulafia, A.; Assia, E.I. Effect of posterior corneal astigmatism on power calculation and alignment of toric intraocular lenses: Comparison of methodologies. J. Cataract Refract. Surg. 2016, 42, 217-225. [CrossRef] [PubMed]

6. $\quad$ Eom, Y.; Rhim, J.W.; Kang, S.; Kim, S.; Song, J.S.; Kim, H.M. Toric intraocular lens calculations using ratio of anterior to posterior corneal cylinder power. Am. J. Ophthalmol. 2015. [CrossRef]

7. Barrett, G.D. An improved universal theoretical formula for intraocular lens power prediction. J. Cataract Refract. Surg. 1993, 19, 713-720. [CrossRef]

8. Kessel, L.; Andresen, J.; Tendal, B.; Erngaard, D.; Flesner, P.; Hjortdal, J. Toric Intraocular Lenses in the Correction of Astigmatism During Cataract Surgery: A Systematic Review and Meta-analysis. Ophthalmology 2016, 123, 275-286. [CrossRef] [PubMed]

9. Hoffer, K.J.; Savini, G. Update on Intraocular Lens Power Calculation Study Protocols. Ophthalmology 2020, in press. [CrossRef]

10. ISO. ISO 11979-7:2018 Ophthalmic Implants-Intraocular Lenses-Part 7: Clinical Investigations of Intraocular Lenses for the Correction of Aphakia; ISO: Geneva, Switzerland, 2018.

11. Armstrong, R.A. Statistical guidelines for the analysis of data obtained from one or both eyes. Ophthalmic Physiol. Opt. 2013, 33, 7-14. [CrossRef]

12. Abulafia, A.; Koch, D.D.; Holladay, J.T.; Wang, L.; Hill, W. Pursuing perfection in intraocular lens calculations: IV. Rethinking astigmatism analysis for intraocular lens-based surgery: Suggested terminology, analysis, and standards for outcome reports. J. Cataract Refract. Surg. 2018, 44, 1169-1174. [CrossRef] [PubMed]

13. Alpins, N.A. A new method of analyzing vectors for changes in astigmatism. J. Cataract Refract. Surg. 1993, 19, 524-533. [CrossRef]

14. Tabachnick, B.G.; Fidell, L.S. Profile analysis: The multivariate approach to repeated measures. In Using Multivariate Statistics; Pearson Education: Boston, MA, USA, 2013; Chapter 8; p. 343.

15. Rodríguez-Vallejo, M. Refractive Analysis. (v.1.0.4). A Matlab Toolbox for the Analysis of Refractive Results in Anterior Segment Surgery. Available online: http:/ / test-eye.com/index.php/en/refractive-analysis (accessed on 1 April 2020).

16. Lehmann, R.P.; Houtman, D.M. Visual performance in cataract patients with low levels of postoperative astigmatism: Full correction versus spherical equivalent correction. Clin. Ophthalmol. 2012, 6, 333. [CrossRef]

17. Hayashi, K.; Manabe, S.I.; Yoshida, M.; Hayashi, H. Effect of astigmatism on visual acuity in eyes with a diffractive multifocal intraocular lens. J. Cataract Refract. Surg. 2010, 36, 1323-1329. [CrossRef]

18. Villegas, E.A.; Alcón, E.; Artal, P. Minimum amount of astigmatism that should be corrected. J. Cataract Refract. Surg. 2014, 40, 13-19. [CrossRef] [PubMed]

19. Koch, D.D.; Jenkins, R.B.; Weikert, M.P.; Yeu, E.; Wang, L. Correcting astigmatism with toric intraocular lenses: Effect of posterior corneal astigmatism. J. Cataract Refract. Surg. 2013, 39, 1803-1809. [CrossRef] [PubMed]

20. Goggin, M.; van Zyl, L.; Caputo, S.; Esterman, A. Outcome of adjustment for posterior corneal curvature in toric intraocular lens calculation and selection. J. Cataract Refract. Surg. 2016, 42, 1441-1448. [CrossRef]

21. Ferreira, T.B.; Ribeiro, P.; Ribeiro, F.J.; O'Neill, J.G. Comparison of astigmatic prediction errors associated with new calculation methods for toric intraocular lenses. J. Cataract Refract. Surg. 2017, 43, 340-347. [CrossRef]

22. Preussner, P.R.; Hoffmann, P.; Wahl, J. Impact of posterior corneal surface on toric intraocular lens (IOL) calculation. Curr. Eye Res. 2015, 40, 809-814. [CrossRef]

23. Nanavaty, M.A.; Teeluck, K.; Bardan, A.S.; Bedi, K.K.; Ali, S. Residual refractive astigmatism following toric intraocular lens implantation without consideration of posterior corneal astigmatism during cataract surgery with low anterior keratometric astigmatism upto 2.5 dioptres. Curr. Eye Res. 2019, 44, 1399-1406. [CrossRef]

24. Yeu, E.; Cheung, A.Y.; Potvin, R. Clinical outcomes of toric intraocular lenses: Differences in expected outcomes when using a calculator that considers effective lens position and the posterior cornea vs. one that does not. Clin. Ophthalmol. 2020, 14, 815-822. [CrossRef]

25. Holladay, J.T.; Pettit, G. Improving toric intraocular lens calculations using total surgically induced astigmatism for a $2.5 \mathrm{~mm}$ temporal incision. J. Cataract Refract. Surg. 2019, 45, 272-283. [CrossRef] 
26. Fernández, J.; Rodríguez-Vallejo, M.; Martínez, J.; Tauste, A.; Piñero, D.P. Prediction of surgically induced astigmatism in manual and femtosecond laser-assisted clear corneal incisions. Eur. J. Ophthalmol. 2018, 28, 398-405. [CrossRef]

27. Li, X.; Chen, X.; He, S.; Xu, W. Effect of 1.8-mm steep-axis clear corneal incision on the posterior corneal astigmatism in candidates for toric IOL implantation. BMC Ophthalmol. 2020, 20, 1-10. [CrossRef] [PubMed]

28. Garzón, N.; Rodríguez-Vallejo, M.; Carmona, D.; Calvo-Sanz, J.A.; Poyales, F.; Palomino, C.; Zato-Gómez de Liaño, M.; Fernández, J. Comparing surgically induced astigmatism calculated by means of simulated keratometry versus total corneal refractive power. Eur. J. Ophthalmol. 2018, 28, 573-581. [CrossRef] [PubMed]

29. Kohnen, T.; Löffler, F.; Herzog, M.; Petermann, K.; Böhm, M. Tomographic analysis of anterior and posterior surgically induced astigmatism after $2.2 \mathrm{~mm}$ temporal clear corneal incisions in femtosecond laser-assisted cataract surgery. J. Cataract Refract. Surg. 2019, 45, 1602-1611. [CrossRef] [PubMed]

30. Kern, C.; Kortüm, K.; Müller, M.; Kampik, A.; Priglinger, S.; Mayer, W.J. Comparison of Two Toric IOL Calculation Methods. J. Ophthalmol. 2018, 2018. [CrossRef]

31. Zhang, L.; Sy, M.E.; Mai, H.; Yu, F.; Rex Hamilton, D. Effect of posterior corneal astigmatism on refractive outcomes after toric intraocular lens implantation. J. Cataract Refract. Surg. 2015, 41, 84-89. [CrossRef]

32. Sano, M.; Hiraoka, T.; Ueno, Y.; Itagaki, H.; Ogami, T.; Oshika, T. Influence of posterior corneal astigmatism on postoperative refractive astigmatism in pseudophakic eyes after cataract surgery. BMC Ophthalmol. 2016, 16, 1-9. [CrossRef]

33. Kane, J.X.; Connell, B. A Comparison of the Accuracy of 6 Modern Toric Intraocular Lens Formulas. Ophthalmology 2020, 127, 1472-1486. [CrossRef]

34. Ueno, Y.; Hiraoka, T.; Beheregaray, S.; Miyazaki, M.; Ito, M.; Oshika, T. Age-related changes in anterior, posterior, and total corneal astigmatism. J. Refract. Surg. 2014, 30, 192-197. [CrossRef] [PubMed] 